\title{
An economic model for the use of yoghurt in type 2 diabetes risk reduction in the UK

Irene Lenoir-Wijnkoop ${ }^{1 *}$, James Mahon², Lindsay Claxton², Alicia Wooding ${ }^{2}$, Andrew Prentice ${ }^{3,4}$ and Nick Finer ${ }^{5}$

\begin{abstract}
Background: In the UK, diabetes accounts for approximately $10 \%$ of the total UK National Health Service (NHS) resource expenditure, a figure that has been predicted to increase to $17 \%$ by $2035 / 2036$. Meta-analysis of association studies indicate that yogurt consumption is potentially protective against type 2 diabetes (T2D). The purpose of this study was to explore the potential economic benefit to the UK NHS of a population increase in yoghurt consumption as a preventative measure against development of T2D.

Methods: A patient simulation model was constructed for adults in the UK over the age of 25 years old using incidence rates for developing T2D with both current and increased yoghurt consumption. The reduction in risk in developing T2D associated with higher yoghurt consumption was taken from a meta-analysis of studies of dairy consumption on T2D risk. In each annual cycle of the model a patient could develop complications and comorbidities that are known to be more common in patients with T2D. Incidence rates for these conditions for diabetics and non-diabetics were taken from published studies. The model had a 25 year time horizon.

Results: The model predicts that increasing average yoghurt consumption by adults over 25 years of age in the UK by $100 \mathrm{~g}$ daily could result in 388,000 fewer people developing T2D over 25 years. This could save the UK NHS £2.3bn in direct T2D treatment costs and the costs of treating T2D associated complications. In addition, 267,000 QALYs would be generated. If the NHS values a QALY valued at $£ 20,000$, this would mean that the NHS should be prepared to pay $£ 5.5 \mathrm{bn}$ for an intervention that generated the same number of QALYS.
\end{abstract}

Conclusions: Increasing yoghurt consumption in the adult population of the UK by $100 \mathrm{~g}$ per day could generate substantial cost savings to the NHS as well as significant patient benefit through reductions in the incidence of T2D.

Keywords: Yoghurt, Type 2 diabetes, T2D, Economic model

\section{Background}

The prevalence of type 2 diabetes (T2D) is rapidly rising and now affects $9 \%$ of the global population [1] and is projected to be the seventh leading cause of death by 2030 [2]. Between 2010 and 2030, the prevalence of diabetes has been forecast to increase by $20 \%$ in developed countries and $69 \%$ in developing counties [3]. In 2015, the costs of diabetes and related complications accounted for $12 \%$ of global healthcare budgets, or between USD673 billion and USD1,197 billion [4]. Lifestyle interventions can prevent or delay some cases of T2D and thus reduce the huge economic burden of diabetes [5]. There is an increasing focus

\footnotetext{
* Correspondence: P.I.Lenoir-Wijnkoop@uu.nl

'Department Pharmaceutical Sciences, Utrecht University, Universiteitsweg 99, 3584 CG Utrecht, The Netherlands

Full list of author information is available at the end of the article
}

on pinpointing food groups that can be used to reduce chronic conditions, and evidence is emerging that dairy products may play an important role in metabolic disease and T2D prevention and management [6]. Dairy products are an important source of protein, fats, vitamins and minerals, but many also contain a proportion of saturated fatty acids (SFAs) [7] which are commonly thought to have a negative effect on cardiometabolic health [8]. However, recent investigations indicate that some types of SFA may actually be beneficial to T2D management; for example, myristic acid has been associated with improved glucose homeostasis $[9,10]$, and plasma levels of very long-chain SFAs were inversely correlated with T2D incidence in the EPIC-InterAct case-cohort study [11]. This may explain why daily consumption of yoghurt has also been linked, in 
a large meta-analysis, to a lower risk of developing $\mathrm{T} 2 \mathrm{D}$, an association that was not seen for general dairy consumption suggesting that the nutritional composition of yoghurt may have specific benefits in T2D prevention [12].

In the UK, diabetes accounts for approximately $10 \%$ of the total UK National Health Service (NHS) resource expenditure, a figure that has been predicted to increase to $17 \%$ by $2035 / 2036$ with $80 \%$ of this cost as a result of complications [13]. Previous econometric research has highlighted the potential cost effectiveness of dietary interventions to prevent or delay the onset of T2D. "The Mediterranean Diet" and the "Intensive Lifestyle Change to Prevent Diabetes" have been cited as highly costeffective interventions gaining $£ 410$ and $£ 750$ per QALY respectively [14]. The American Diabetes Association (ADA) recommend several interventions for preventing and treating T2D; a systematic review from 2010 indicated that preventative interventions were the most cost-effective, with the strongest evidence available for "primary prevention through lifestyle modification" [15]. The purpose of this study was to explore the potential economic benefit to the UK of an increase in yoghurt consumption as a preventative measure against development of T2D.

\section{Methods}

The primary research question was: How would an increase in the average consumption of conventional yoghurt impact upon UK health care expenditure in the management and treatment of T2D? A supplementary research question was: How would an increase in the average consumption of conventional yoghurt impact upon the quality and length of life for a UK population based on cases of T2D avoided or delayed?

\section{The model}

The patient pathway is shown in Fig. 1 and was used to build a patient simulation model in Microsoft Excel. To summarise the pathway, a virtual subject enters the

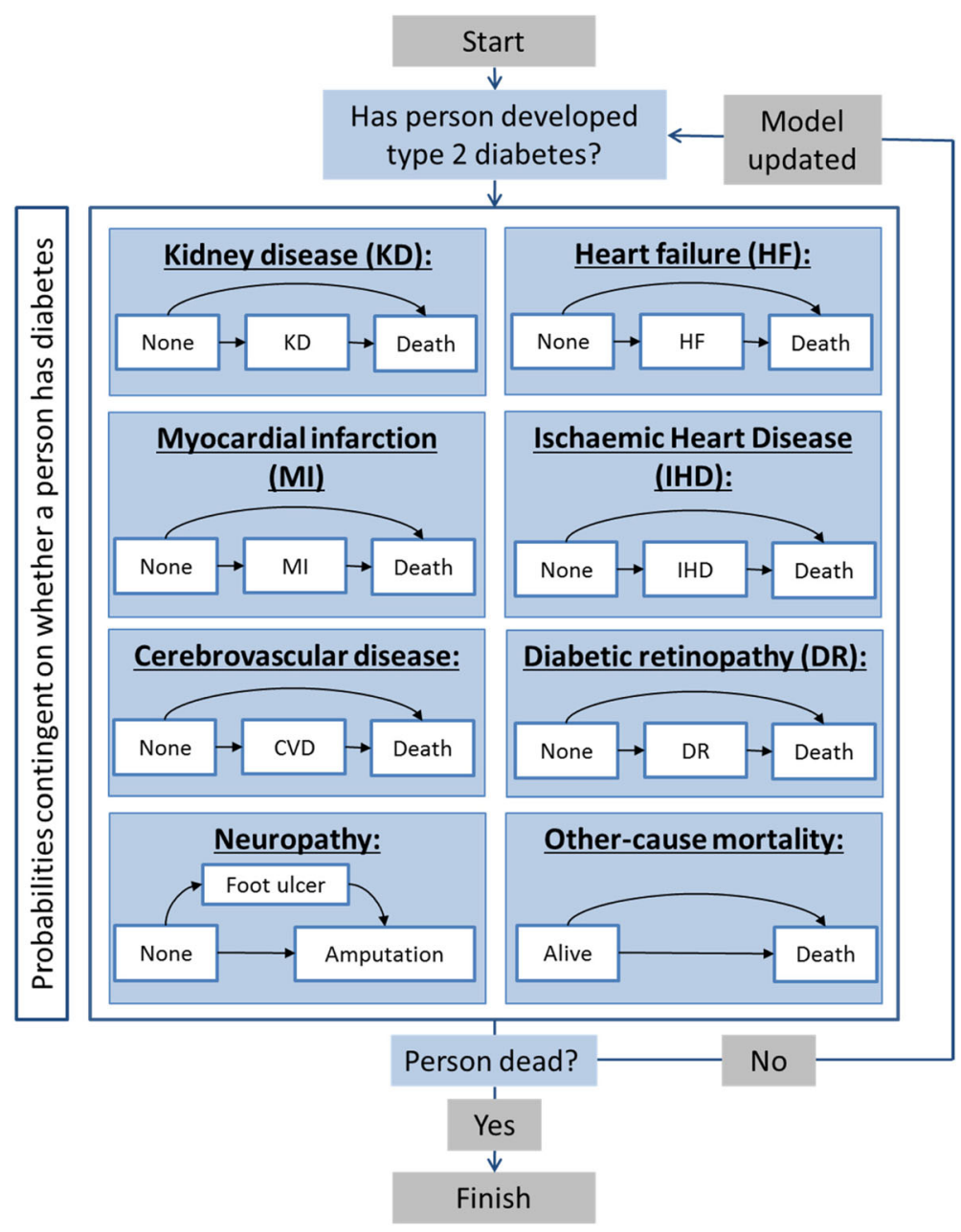

Fig. 1 Patient pathway 
model with randomly assigned characteristics (age, gender, pre-existing conditions). If he/she does not already have T2D, the risk of developing the disease in each subsequent year is reduced by higher yoghurt consumption. In the model, each year a subject can develop one or several complications, or die; for a subject who already has T2D, the probability of developing a complication is increased.

The modelled population was all people in the UK aged over 25 years. Age and gender distributions were taken from the Office for National Statistics (ONS) population pyramid projections [16].

\section{Effectiveness}

Effectiveness was derived from Chen et al. [12], a large study, combining 14 prospective cohorts and a total of 459,790 individuals, with 35,863 developing T2D within 4 million patient-years of follow-up. Based upon a correlation between yoghurt consumption and developing T2D, Chen estimated that for each additional serving of $244 \mathrm{~g}$ of yoghurt, the relative risk (RR) of developing T2D is 0.82 . To undertake our modelling, we assumed that the relationship was causative and that risk reduction occurs linearly with changes in yoghurt consumption and adjusted for current average yoghurt consumption in the UK of $20.4 \mathrm{~g}$ per person per day [17]. In the base case model it was assumed that average daily consumption would rise by $100 \mathrm{~g}$ to reach $125 \mathrm{~g}$ (a standard size single serving 'pot' in the UK). This equated to a change in the RR of developing T2D from 0.99 at current consumption, to 0.91 if average consumption increased to $125 \mathrm{~g}$ daily. The RRs were estimated using a linear interpolation between the $R R$ associated with no daily yoghurt consumption $(0 \mathrm{~g}, \mathrm{RR}=1)$, and the $R R$ associated with a daily serving $(244 \mathrm{~g}, \mathrm{RR}=0.82)$.

\section{Costs}

Throughout the model we have taken a conservative approach. Costs incorporated into the model are considered in three categories: direct diabetes management costs; hospital; and non-inpatient costs for treating diabetes-related complications.

Diabetes management costs were taken from Hex et al. [13], who reported a mean direct treatment cost (including diabetic medications, primary care visits, retinopathy screening, influenza vaccination and medical examinations) of $£ 513.54$ per person with diabetes to the UK NHS.

For treatment of complications, costs and resource use were modelled using a recently published logit model that looked at the UKPDS data on healthcare costs [18]. Costs included those for all admissions and inpatient procedures as well as outpatient consultations with GPs, nurses, health visitors, dieticians, chiropodists and eye care specialists. Whether a condition required initial hospitalisation and/or annual on-going treatment post discharge was modelled through a random drawing of the logit model. Parameters of the logit model are summarised in Table 1.

The model conservatively considered that the probability of experiencing a particular event, or developing a condition was independent of the presence of others. However, the costs that could be incurred when an event or condition arises could be dependent on the presence of other conditions. For example, having a stroke would not make it more likely a person had a myocardial infarction (MI) in the future but it would make it more likely that an MI would lead to hospitalisation. Other than for foot ulcers (which were considered as a one off certainty of the cost of the event), only the first event of each complication was considered in the model.

Specific additional costs were also identified to complete the necessary inputs into the model:

- Heart failure and diabetic retinopathy - derived in Sheffield Diabetes model (SDM) from older UKPDS data [19];

- CKD - derived in SDM from NHS reference costs [20];

- Foot ulcer - NHS diabetic foot care report [21].

\section{Quality of Life}

At the end of each cycle a person exists in an age and disease specific health state. Each health state has an associated level of quality of life that is measured via utility estimates from the literature. With the exception of amputation, all utility values were derived from Sullivan [22] that estimated health states from 80,000 people in the USA and applied UK utility weights to these health states. For lower limb amputation, a utility value was taken from Bagust [23].

The age and disease utility decrements used in the model are given in Table 2. For cardiovascular conditions, the maximum decrement of the three possible conditions in the model was applied if more than one of the conditions was experienced.

Once a condition is experienced, that utility decrement exists for the remainder of the patient's life (with the exception of foot ulcers). It is noted that the utility value is an average value of people with both good and poor outcomes after events.

\section{Disease incidence and prevalence rates}

Age specific prevalence rates of T2D and age and gender specific prevalence rates of related comorbidities were required to be able to estimate the likelihood of an individual entering the model, already having T2D or an associated comorbidity (with or without the presence of 
Table 1 Logit model values of costs associated with treating complications of T2D

\begin{tabular}{|c|c|c|c|c|c|}
\hline & Variable & Logit model coefficient & Hospital care $(£)$ & Non-patient care $(£)$ & Additional $(£)$ \\
\hline & Constant & -1.353 & 3318 & 531 & - \\
\hline & Aged 65+ & 0.041 & 38 & 4 & - \\
\hline & Male & -0.118 & -218 & -162 & - \\
\hline \multirow[t]{13}{*}{ Event during current year } & Ischaemic heart disease (angina) & 3.379 & 8636 & 331 & - \\
\hline & Fatal Ischaemic heart disease & 4.701 & 1037 & - & - \\
\hline & Heart failure & 2.98 & 1147 & 447 & - \\
\hline & Fatal heart failure & - & - & - & 3637 \\
\hline & Myocardial infarction & 4.506 & 3845 & 963 & - \\
\hline & Fatal myocardial infarction & 5.115 & -1341 & - & - \\
\hline & CKD requiring $\mathrm{RRT}$ & - & - & - & 23275 \\
\hline & Stroke & 2.419 & 7133 & 559 & - \\
\hline & Fatal stroke & - & 1042 & - & - \\
\hline & Diabetic retinopathy & - & - & - & 138 \\
\hline & Blindness in one eye & 0.825 & 1621 & 1258 & - \\
\hline & Foot ulcer & - & - & - & 743.68 \\
\hline & Amputation & 4.059 & 7516 & 2166 & - \\
\hline \multirow[t]{6}{*}{ Historic event } & Ischaemic heart disease (angina) & 0.553 & 2042 & 121 & - \\
\hline & Heart failure & 0.824 & 2017 & 441 & - \\
\hline & Myocardial infarction & 0.68 & 1369 & 671 & - \\
\hline & Stroke & 0.37 & 2371 & 224 & - \\
\hline & Blindness in one eye & 0.266 & -601 & 205 & - \\
\hline & Amputation & 1.254 & 1616 & 1079 & - \\
\hline
\end{tabular}

T2D). Similarly, age related incidence rates were required to move people through the model during each annual cycle. The source of each of the incidence and prevalence rates is shown in Table 3.

\section{Relative risks of comorbid disease with T2D}

The National Diabetes Audit 2011-2012 provided data on the relative increase in the risk of comorbid disease for people with T2D [24]. The audit recorded data from

Table 2 Utility decrements applied in the model

\begin{tabular}{lc}
\hline Condition & Decrement \\
\hline Age (per year) & -0.00029 \\
Diabetes & -0.07 \\
Ischemic heart disease & -0.09 \\
Heart failure & -0.12 \\
Myocardial infarction & -0.06 \\
CKD requiring RRT & -0.11 \\
Cerebrovascular disease (stroke) & -0.10 \\
Diabetic retinopathy & -0.04 \\
Blindness & -0.06 \\
Foot ulcer & -0.07 \\
Amputation & -0.11 \\
\hline
\end{tabular}

2.5 million people in England and Wales. The increase in risk for each condition is shown in Table 4.

\section{Mortality}

Mortality occurs in the model in two distinct ways; a person may die from developing a particular condition or event, such as cerebrovascular disease (stroke) or MI; or a person may suffer an 'all-other cause death' based upon age and gender derived all-cause mortality data. Individual condition/event mortality rates were taken from published sources shown in Table 5 and all other cause mortality was sourced from the ONS [16].

\section{Results}

Results under the base case assumptions for 100,000 individuals cycled through the model were generated. The average individual and total (extrapolated to all people in the UK over 25) cost savings and QALY gains from higher yoghurt consumption are shown in Tables 6 and 7.

The base case results - which are based on a conservative approach to modelling potential benefits - show that if the average daily consumption of yoghurt in the UK for people over the age of 25 increased from $20.4 \mathrm{~g}$ to a $125 \mathrm{~g}$ serving, discounted mean savings over five 
Table 3 Model disease incidence and prevalence rates

\begin{tabular}{lll}
\hline Condition & Prevalence source & Incidence source \\
\hline Diabetes (Type 2) & Scottish Diabetes Survey 2013 [31] & Scottish Diabetes Survey 2013 [31] \\
Ischemic heart disease & British Heart Foundation 2012 [32] & British Heart Foundation 2012 [32] \\
Heart failure & Welsh Health Survey 2010 [33] & British Heart Foundation 2012 [32] \\
Myocardial infarction & British Heart Foundation 2012 [32] & British Heart Foundation 2012 [32] \\
Renal replacement therapy (RRT) & The Renal Registry 2012 [34] & EUGLOREH [35] \\
Cerebrovascular disease (stroke) & British Heart Foundation 2012 [32] & Oxford Vascular study [36] \\
Diabetic retinopathy & Zhang et al. (2010) [37] & DARTS diabetes register McAlpine et al. (2005) [38] \\
Blindness & Prasad et al. (2001) [39] & Trautner et al. (2003) [40] \\
Neuropathy & Abbott et al. (2001) [41] & Abbott et al. (2002) [41] \\
Lower limb amputation & Ahmad et al. (2014) [42] & Johannesson et al. (2009) [43] \\
\hline
\end{tabular}

years to the NHS from reducing the rate of T2D and T2D related complications would be $£ 3.21$ (95\% CI: $£ 2.65, £ 3.77)$ per person. This saving would increase each year up to and including the 25 years considered in the model. By 25 years the saving per person from increased yoghurt consumption would be $£ 54.35$ ( $£ 49.87$, £58.82).

Applying the average saving to the UK population over the age of 25 would generate total discounted savings to the NHS of approximately $£ 140$ million ( $£ 116 \mathrm{~m}, £ 165 \mathrm{~m})$ over five years that would increase to $£ 2,377$ million $(£ 2,181 \mathrm{~m}, £ 2,573 \mathrm{~m})$ over 25 years if average consumption increased to $125 \mathrm{~g}$.

From a quality of life perspective, if the average consumption of yoghurt by people over 25 in the UK increased to $125 \mathrm{~g}$ per day, an average additional 0.0004 discounted QALYs $(0.0003,0.0005)$ per person over five years would be generated; this would increase to an additional 0.0063 discounted QALYs (0.0056 to 0.0070) after 25 years. At a population level this would generate approximately $276,352(246,172,306,532)$ total additional discounted QALYs over 25 years. If these QALYs were valued at $£ 20,000 / Q A L Y$ as is usually applied by NICE in the UK for approval of therapies, then the NHS should be prepared to pay $£ 5,500$ m over 25 years for an intervention that would generate the same number of QALYs.

Application of the 0.91 risk reduction of developing T2D from average yoghurt consumption of $125 \mathrm{~g}$ as

Table 4 Increase in risk of conditions with T2D

\begin{tabular}{ll}
\hline Disease & Increase in risk \\
\hline Ischemic heart disease & $76 \%$ \\
Heart failure & $73 \%$ \\
Myocardial infarction & $55 \%$ \\
RRT & $64 \%$ \\
Cerebrovascular disease (stroke) & $34 \%$ \\
Lower limb amputation & $287 \%$ \\
\hline
\end{tabular}

opposed to the 0.99 risk reduction from the current average of $20.4 \mathrm{~g}$ has a relatively modest impact on the absolute annual risk of developing T2D in the model. For people aged $60-69$, the annual risk of developing T2D in the model is reduced from $0.67 \%$ to $0.62 \%$, which was the largest absolute reduction for any age group. However whilst the annual absolute risk reduction is modest, over time this reduction results in a substantial number of avoided incident cases of T2D.

In the base case, the model suggests that the absolute reduction in the 25-year risk of developing T2D for a random person over the age of 25 was $0.89 \%$ ( $0.83 \%$ to $0.95 \%)$. At a population level, this equates to 388,369 $(362,939$ to 413,800$)$ fewer people developing T2D over 25 years.

From this reduction in the risk of developing T2D there is a consequent reduction in the risk of developing the complications of T2D. This in turn could reduce the NHS burden of treating those complications for each individual as well as increases an individual's quality of life. Specifically over 25 years the modelling predicts that consumption of an additional daily serving of yoghurt in the whole adult population over 25 years old in the UK would reduce the number of people with:

- A first cerebrovascular event (stroke) by 4,811 (95\% CI: 1,968, 7,654);

- Ischemic heart disease by 3,499 (1,074, 5,923);

- Heart failure by $1,749(35,3,464)$;

Table 5 Source of mortality rates

\begin{tabular}{ll}
\hline Disease & Source \\
\hline Ischemic heart disease & NICE CG108. (2006) [44] \\
Heart failure, year one & Cowie et al. (2000) [45] \\
Heart failure, after year one & Hobbs et al. (2007) [46] \\
Myocardial infarction & British Heart Foundation 2012 [32] \\
RRT & The Renal Registry 2012 [34] \\
Cerebrovascular disease (stroke) & British Heart Foundation 2012 [32] \\
\hline
\end{tabular}


Table 6 Estimated base case individual and total UK costs and savings over 25 years for an average daily yoghurt intake of $125 \mathrm{~g}$. (Means and 95\% Cl)

\begin{tabular}{|c|c|c|c|c|c|c|}
\hline \multirow[b]{2}{*}{ Costs } & \multicolumn{3}{|c|}{ Individual (average) costs } & \multicolumn{3}{|l|}{ UK population costs } \\
\hline & Current scenario & Yoghurt scenario & Savings & Current scenario & Yoghurt scenario & Savings \\
\hline 5 Years & $\begin{array}{l}£ 5,984 \\
(£ 5,966, £ 6,002)\end{array}$ & $\begin{array}{l}£ 5,981 \\
(£ 5,963, £ 5,998)\end{array}$ & $\begin{array}{l}£ 3.21 \\
(£ 2.65, £ 3.77)\end{array}$ & $\begin{array}{l}£ 261,710 \mathrm{~m} \\
(£ 260,941 \mathrm{~m}, £ 262,480 \mathrm{~m})\end{array}$ & $\begin{array}{l}£ 261,570 \mathrm{~m} \\
(£ 260,801 \mathrm{~m}, £ 262,339 \mathrm{~m})\end{array}$ & $\begin{array}{l}£ 140 \mathrm{~m} \\
(£ 116 \mathrm{~m}, £ 165 \mathrm{~m})\end{array}$ \\
\hline 10 Years & $\begin{array}{l}£ 10,883 \\
(£ 10,854, £ 10,911)\end{array}$ & $\begin{array}{l}£ 10,871 \\
(£ 10,842, £ 10,900)\end{array}$ & $\begin{array}{l}£ 11.6 \\
(£ 10.09, £ 13.1)\end{array}$ & $\begin{array}{l}£ 475,955 \mathrm{~m} \\
(£ 474,697 \mathrm{~m}, £ 477,214 \mathrm{~m})\end{array}$ & $\begin{array}{l}£ 475,448 m \\
(£ 474,192 m, £ 476,705 m)\end{array}$ & $\begin{array}{l}£ 507 m \\
(£ 441 m, £ 573 m)\end{array}$ \\
\hline 15 Years & $\begin{array}{l}£ 15,028 \\
(£ 14,990, £ 15,067)\end{array}$ & $\begin{array}{l}£ 15,005 \\
(£ 14,966, £ 15,043)\end{array}$ & $\begin{array}{l}£ 23.65 \\
(£ 21.08, £ 26.23)\end{array}$ & $\begin{array}{l}£ 657,270 \mathrm{~m} \\
(£ 655,579 \mathrm{~m}, £ 658,961 \mathrm{~m})\end{array}$ & $\begin{array}{l}£ 656,235 \mathrm{~m} \\
(£ 654,549 \mathrm{~m}, £ 657,922 \mathrm{~m})\end{array}$ & $\begin{array}{l}£ 1,034 \mathrm{~m} \\
(£ 922 \mathrm{~m}, £ 1,147 \mathrm{~m})\end{array}$ \\
\hline 20 Years & $\begin{array}{l}£ 18,547 \\
(£ 18,499, £ 18,595)\end{array}$ & $\begin{array}{l}£ 18,509 \\
(£ 18,461, £ 18,557)\end{array}$ & $\begin{array}{l}£ 37.91 \\
(£ 34.31, £ 41.51)\end{array}$ & $\begin{array}{l}£ 811,149 \mathrm{~m} \\
(£ 809,049 \mathrm{~m}, £ 813,249 \mathrm{~m})\end{array}$ & $\begin{array}{l}£ 809,491 \mathrm{~m} \\
(£ 807,397 \mathrm{~m}, £ 811,584 \mathrm{~m})\end{array}$ & $\begin{array}{l}£ 1,658 \mathrm{~m} \\
(£ 1,500 \mathrm{~m}, £ 1,816 \mathrm{~m})\end{array}$ \\
\hline 25 Years & $\begin{array}{l}£ 21,493 \\
(£ 21,436, £ 21,550)\end{array}$ & $\begin{array}{l}£ 21,438 \\
(£ 21,382, £ 21,495)\end{array}$ & $\begin{array}{l}£ 54.35 \\
(£ 49.87, £ 58.82)\end{array}$ & $\begin{array}{l}£ 939,994 m \\
(£ 937,509 m, £ 942,480 m)\end{array}$ & $\begin{array}{l}£ 937,617 m \\
(£ 935,140 m, £ 940,095 m)\end{array}$ & $\begin{array}{l}£ 2,377 \mathrm{~m} \\
(£ 2,181 \mathrm{~m}, £ 2,573 \mathrm{~m})\end{array}$ \\
\hline
\end{tabular}

\section{Estimated UK population cost savings}

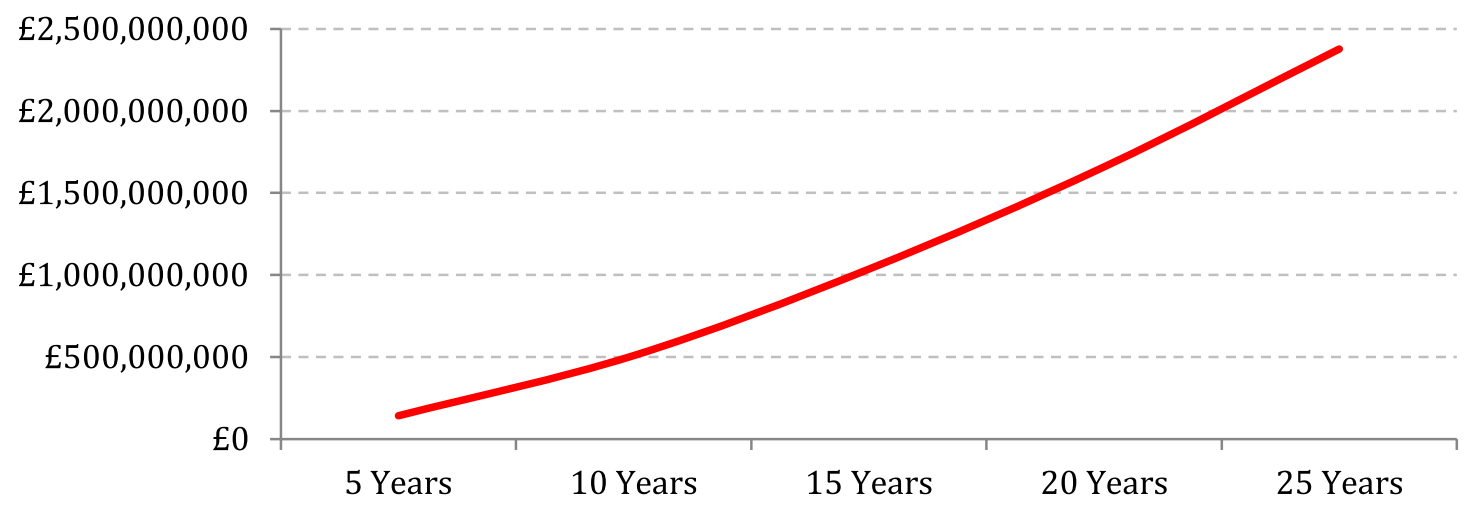

- A first myocardial infarction by $1,749(35,3,464)$;

- Requiring RRT by 437 (-420, 1,295);

- Diabetic neuropathy by 13,558 (8,786 to 18,330$)$;

- Lower limb amputation by 3,936 (1,365 to 6,508$)$.

The biggest driver of both cost savings and QALY gains in the model results from the reduction in people with T2D itself rather than a reduction in complications. Savings from direct treatment costs of T2D accounts for $91.5 \%$ of the total model savings and approximately $85 \%$ of the QALY gains.

The model also suggested that increased yoghurt consumption to an average of $125 \mathrm{~g}$ per day would reduce overall mortality over 25 years by $0.005 \%(0.001 \%$ to $0.009 \%$ ). This equates to there being 2,187 (95\% CI: 270 to 4,104$)$ more people who would still be alive after 25 years if yoghurt consumption increased to an average of $125 \mathrm{~g}$.

We undertook sensitivity analyses of the lower and upper confidence interval for the risk reduction of an extra daily serving of yoghurt on T2D risk reported in Chen adjusted for $125 \mathrm{~g}$ consumption (0.85 to 0.98). This results in a potential saving to the NHS of an increase in average consumption to $125 \mathrm{~g}$ a day at a population level of between $£ 0.48$ billion and $£ 3.80$ billion. QALY savings generated varied between 60,940 and 429,831 and deaths averted between 1,749 and 4,374.

\section{Discussion}

We have demonstrated that if the correlation relationship reported in Chen of increasing yoghurt consumption is causative, then increasing yoghurt consumption could be an effective policy for reducing the incidence of T2D. The patient-level simulation model predicts that if in the UK the average consumption of yoghurt increased from $20.4 \mathrm{~g}$ to $125 \mathrm{~g}$ daily (an additional $100 \mathrm{~g}$ ) in people over the age of 25 years old, nearly 400,000 fewer people would develop T2D over the next 25 years. Such an approach fits well with National Institute for Health and Clinical Excellence (NICE) 2015 Clinical Guidelines to integrate dietary advice into prevention and treatment of T2D, as well as United Nation goals to reduce the impact of non-communicable diseases (NCDs), such as T2D, by reducing modifiable risk factors for NCDs associated with unhealthy diet, physical inactivity and obesity [25].

In terms of the NHS, an increase in the average consumption of conventional yoghurt could help attenuate 
Table 7 Estimated base case individual and total UK QALYs and savings over 25 years for an average daily yoghurt intake of $125 \mathrm{~g}$

\begin{tabular}{|c|c|c|c|c|c|c|}
\hline \multirow[b]{2}{*}{ QALYS } & \multicolumn{3}{|c|}{ Individual (average) QALYs } & \multicolumn{3}{|c|}{ UK population QALYs } \\
\hline & Current scenario & Yoghurt scenario & Gained QALYS & Current scenario & Yoghurt scenario & Gained QALYS \\
\hline 5 Years & $\begin{array}{l}4.3743 \\
(4.3684,4.3803)\end{array}$ & $\begin{array}{l}4.3747 \\
(4.3687,4.3807)\end{array}$ & $\begin{array}{l}4.3743 \\
(4.3684,4.3803)\end{array}$ & $\begin{array}{l}191 m \\
(191 m, 192 m)\end{array}$ & $\begin{array}{l}191 m \\
(191 m, 192 m)\end{array}$ & $\begin{array}{l}0.017 \mathrm{~m} \\
(0.015 \mathrm{~m}, 0.020 \mathrm{~m})\end{array}$ \\
\hline 10 Years & $\begin{array}{l}8.0515 \\
(8.0372,8.0657)\end{array}$ & $\begin{array}{l}8.0528 \\
(8.0386,8.067)\end{array}$ & $\begin{array}{l}8.0515 \\
(8.0372,8.0657)\end{array}$ & $\begin{array}{l}352 m \\
(352 m, 353 m)\end{array}$ & $\begin{array}{l}352 m \\
(352 m, 353 m)\end{array}$ & $\begin{array}{l}0.060 \mathrm{~m} \\
(0.052 \mathrm{~m}, 0.067 \mathrm{~m})\end{array}$ \\
\hline 15 Years & $\begin{array}{l}11.1406 \\
(11.1175,11.1637)\end{array}$ & $\begin{array}{l}11.1434 \\
(11.1203,11.1665)\end{array}$ & $\begin{array}{l}11.1406 \\
(11.1175,11.1637)\end{array}$ & $\begin{array}{l}487 m \\
(486 m, 488 m)\end{array}$ & $\begin{array}{l}487 m \\
(486 m, 488 m)\end{array}$ & $\begin{array}{l}0.124 m \\
(0.109 m, 0.139 m)\end{array}$ \\
\hline 20 Years & $\begin{array}{l}13.6927 \\
(13.6608,13.7245)\end{array}$ & $\begin{array}{l}13.6973 \\
(13.6654,13.7291)\end{array}$ & $\begin{array}{l}13.6927 \\
(13.6608,13.7245)\end{array}$ & $\begin{array}{l}599 m \\
(597 m, 600 m)\end{array}$ & $\begin{array}{l}599 m \\
(598 m, 600 m)\end{array}$ & $\begin{array}{l}0.200 \mathrm{~m} \\
(0.177 \mathrm{~m}, 0.223 \mathrm{~m})\end{array}$ \\
\hline 25 Years & $\begin{array}{l}15.7573 \\
(15.7172,15.7975)\end{array}$ & $\begin{array}{l}15.7637 \\
(15.7235,15.8038)\end{array}$ & $\begin{array}{l}15.7573 \\
(15.7172,15.7975)\end{array}$ & $\begin{array}{l}689 m \\
(687 m, 691 m)\end{array}$ & $\begin{array}{l}689 m \\
(688 m, 691 m)\end{array}$ & $\begin{array}{l}0.276 \mathrm{~m} \\
(0.246 \mathrm{~m}, 0.307 \mathrm{~m})\end{array}$ \\
\hline
\end{tabular}

Estimated UK population QALY gains

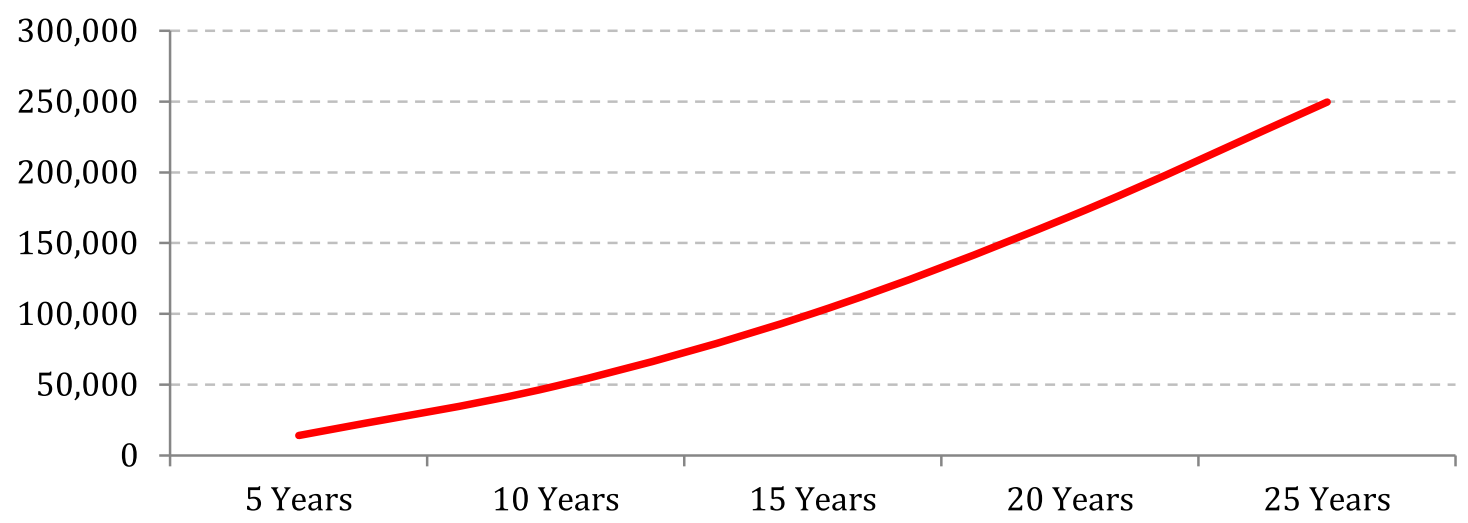

NHS expenditure on diabetes already predicted to increase to $17 \%$ of the total resources by 2035 [13]. Applying the average saving to the UK population over the age of 25 would generate total discounted savings to the NHS of approximately $£ 140$ million over five years that would increase to $£ 2.4$ billion over 25 years if average consumption increased to $125 \mathrm{~g}$.

Additional benefits from increased yoghurt consumption might accrue from direct effects on cardiovascular risks. Evidence that fatty acids in dairy may help improve glucose homeostasis [9], and daily consumption of probiotic yoghurt has the potential to improve cardiovascular disease risk factors associated with diabetes [26], provides a rationale for incorporating the consumption of yoghurt into this dietary advice.

Yoghurt consumption can also be recommended in addition to other, more targeted interventions, as the financial cost of purchasing the yoghurt falls upon the individual rather than the NHS; if the yoghurt was a replacement for other snacks rather than an additional snack, the cost to the individual might be negligible. In a recently published meta-analysis, Gijsbers supports the findings of the Chen study indicating that yoghurt intake may be non-linearly associated with lower risk of T2D, reporting a $14 \%$ lower risk for an intake of 80 to $125 \mathrm{~g}$ per day compared with zero consumption, which appears to be in line with the absolute risk reduction of our base case [27].

Given the rapidly increasing prevalence of $\mathrm{T} 2 \mathrm{D}$, the findings of this research offer implications for costsaving measures which could help alleviate the economic burden of T2D, and relieve pressure on the health care infrastructures in the long term in populations beyond the UK.

\section{Limitations in model}

All the analyses related to individuals over the age of 25 and so the model and economic results generated are only for people over the age of 25 years old; however this is reasonable for the condition as T2D is more common after the age of 45 [28].

The Chen meta-analysis [12], on which this research is based, provided longitudinal data from a large number of patients which provides evidence on the RR of developing T2D with different levels of yoghurt consumption based upon the correlation between the two. The Chen data was pooled from retrospective food frequency questionnaires capturing participant food intake over the course of a year, 
so there is likely to be some recall bias in reporting amounts of foods consumed. Chen compiled data from prospective cohort studies, which allows establishment of statistical associations between events. This does not provide direct proof of effect, individual studies have as much as possible adjusted for confounding factors but the possibility of residual confounding cannot be discarded. To demonstrate causality, randomised controlled intervention trials of increasing yoghurt consumption would be needed. It may be that such studies, including in individuals under 25 years old [29], should now be planned and undertaken. The Chen meta-analysis did not differentiate between plain, flavoured and sweetened yoghurt. Results from 3 recent prospective cohorts indicate that weight loss is observed even with sweetened yoghurt consumption, although the benefit is higher for those who eat yoghurt with a low glycaemic load [10]. In addition, it has been reported that, when observing consumer sweetening behaviour in contextualised conditions, on average a greater amount of sugar is added in plain yoghurt than that found in commercial pre-sweetened yoghurts [30]. Further research could investigate differences in diabetes incidence rates across the various types of yoghurt.

\section{Conclusions}

Increasing yoghurt consumption in the adult population of the UK by $100 \mathrm{~g}$ per day could generate substantial cost savings to the NHS as well as significant patient benefit through reductions in the incidence of T2D if the causal relationship between yoghurt consumption and reduced levels of diabetes seen in published studies is confirmed.

\section{Abbreviations}

ADA: American Diabetes Association; MI: Myocardial infarction; NICE: National Institute for Health and Clinical Excellence; ONS: Office for National Statistics; RRT: Renal replacement therapy; SFAs: Saturated fatty acids; SDM: Sheffield Diabetes model; T2D: Type 2 diabetes

\section{Acknowledgements}

Not applicable.

\section{Funding}

This research was funded by an unrestricted grant from Danone Institute International (DII).

\section{Availability of data and materials}

Logit models value table and model probabilities data can be found at https://figshare.com/s/0637618c5aa76c64515f.

\section{Authors' contributions}

ILW and AP initiated the study, JM and LC designed and developed the economic model. NF, AP and ILW provided guidance. ILW coordinated the work throughout, NF and AP validated the model assumptions. JM and LC did the data analysis. All authors participated in the literature review, selection of sources and contributed to the interpretation of the analysis outcomes. AW drafted the initial and subsequent versions of the manuscript. $N F, A P, L C, J M$ and ILW critically reviewed each draft of the manuscript. All authors approved the final version of the manuscript.

\section{Competing interests}

ILW is employed by the Danone Company, France. AMP is a member of the board of the Yogurt in Nutrition Initiative (YINI) supported by Danone Institutes International and has received travel support and honoraria. NF is employed by Novo Nordisk A/S, Denmark.

\section{Consent for publication}

Not applicable.

\section{Ethics approval and consent to participate}

Not applicable.

\section{Author details}

${ }^{1}$ Department Pharmaceutical Sciences, Utrecht University, Universiteitsweg 99, 3584 CG Utrecht, The Netherlands. ${ }^{2}$ York Health Economics Consortium (YHEC), Enterprise House, Innovation Way, University of York, York YO10 5NQ, UK. ${ }^{3}$ MRC Unit The Gambia, Atlantic Blvd, Serrekunda, The Gambia. ${ }^{4}$ MRC International Nutrition Group, London School of Hygiene \& Tropical Medicine, Keppel St, London WC1E 7HT, UK. ${ }^{5}$ National Centre for Cardiovascular Prevention and Outcomes, UCL Institute of Cardiovascular Science, 1 St Martin's le Grand, London EC1A 4NP, UK.

Received: 16 June 2016 Accepted: 21 November 2016

Published online: 28 December 2016

\section{References}

1. World Health Organization. Global status report on noncommunicable diseases. Geneva: WHO; 2014.

2. Mathers $C D$, Loncar D. Projections of global mortality and burden of disease from 2002 to 2030. PLoS Med. 2006;3(11):e442.

3. Shaw JE, Sicree RA, Zimmet PZ. Global estimates of the prevalence of diabetes for 2010 and 2030. Diabetes Res Clin Pract. 2010;87(1):4-14.

4. International Diabetes Federation. IDF Diabetes atlas: seventh edition. Brussels: IDF; 2015

5. Diabetes Prevention Program Research Group. The 10-year costeffectiveness of lifestyle intervention or metformin for diabetes prevention: an intent-to-treat analysis of the DPP/DPPOS. Diabetes Care. 2012;35(4):72330.

6. Panahi S, Tremblay A. The Potential Role of Yogurt in Weight Management and Prevention of Type 2 Diabetes. J Am Coll Nutr. 2016;35(8):717-31.

7. Månsson HL. Fatty acids in bovine milk fat. Food Nutr Res. 2008:52:10.3402/ fnr.v52i0.1821. doi:10.3402/fnr.v52i0.1821.

8. Phillips CM, Kesse-Guyot E, McManus R, Hercberg S, Lairon D, Planells R, Roche HM. High dietary saturated fat intake accentuates obesity risk associated with the fat mass and obesity-associated gene in adults. J Nutr. 2012;142(5):824-31.

9. Drehmer M, Pereira MA, Schmidt MI, Del Carmen BMM, Alvim S, Lotufo PA, Duncan BB. Associations of dairy intake with glycemia and insulinemia, independent of obesity, in Brazilian adults: the Brazilian Longitudinal Study of Adult Health (ELSA-Brasil). Am J Clin Nutr. 2015;101(4):775-82.

10. Smith JD, Hou T, Ludwig DS, Rimm EB, Willett W, Hu FB, Mozaffarian D. Changes in intake of protein foods, carbohydrate amount and quality, and long-term weight change: results from 3 prospective cohorts. Am J Clin Nutr. 2015;101(6):1216-24.

11. Forouhi NG, Koulman A, Sharp SJ, Imamura F, Kroger J, Schulze MB, Crowe FL, Huerta JM, Guevara M, Beulens JW, et al. Differences in the prospective association between individual plasma phospholipid saturated fatty acids and incident type 2 diabetes: the EPIC-InterAct case-cohort study. Lancet Diabetes Endocrinol. 2014;2(10):810-8.

12. Chen M, Sun Q, Giovannucci E, Mozaffarian D, Manson JE, Willett WC, Hu FB. Dairy consumption and risk of type 2 diabetes: 3 cohorts of US adults and an updated meta-analysis. BMC Med. 2014;12:215.

13. Hex N, Bartlett C, Wright D, Taylor M, Varley D. Estimating the current and future costs of Type 1 and Type 2 diabetes in the UK, including direct health costs and indirect societal and productivity costs. Diabet Med. 2012;29(7):855-62.

14. Dalziel K, Segal L. Time to give nutrition interventions a higher profile: cost-effectiveness of 10 nutrition interventions. Health Promot Int. 2007;22(4):271-83. 
15. Li R, Zhang P, Barker LE, Chowdhury FM, Zhang X. Cost-effectiveness of interventions to prevent and control diabetes mellitus: a systematic review. Diabetes Care. 2010;33(8):1872-94.

16. Age Structure of United Kingdom 1971- 2085 [http://webarchive. nationalarchives.gov.uk/20160105160709/http://www.ons.gov.uk/ons/ dcp171776_237753.pdf].

17. O'Connor LM, Lentjes MA, Luben RN, Khaw KT, Wareham NJ, Forouhi NG. Dietary dairy product intake and incident type 2 diabetes: a prospective study using dietary data from a 7-day food diary. Diabetologia. 2014;57(5):909-17.

18. Alva ML, Gray A, Mihaylova B, Leal J, Holman RR. The impact of diabetesrelated complications on healthcare costs: new results from the UKPDS (UKPDS 84). Diabet Med. 2015;32(4):459-66.

19. Stevens RJ, Kothari V, Adler Al, Stratton IM. United Kingdom Prospective Diabetes Study G: The UKPDS risk engine: a model for the risk of coronary heart disease in Type II diabetes (UKPDS 56). Clin Sci (Lond). 2001;101(6):671-9.

20. Kothari V, Stevens RJ, Adler Al, Stratton IM, Manley SE, Neil HA, Holman RR. UKPDS 60: risk of stroke in type 2 diabetes estimated by the UK Prospective Diabetes Study risk engine. Stroke. 2002;33(7):1776-81.

21. Kerr M. In: Economics IH, editor. NHS Diabetes: Foot care for people with diabetes: The economic case for change. 2012. p. 1-72.

22. Sullivan PW, Slejko JF, Sculpher MJ, Ghushchyan V. Catalogue of EQ-5D scores for the United Kingdom. Med Decis Mak. 2011;31(6):800-4

23. Bagust A, Beale S. Modelling EuroQol health-related utility values for diabetic complications from CODE-2 data. Health Econ. 2005;14(3):217-30.

24. National Diabetes Audit 2011-2012. Report 2: Complications and mortality. Published by the Health and Social Care Information Centre (HSCIC); 2013. http://content.digital.nhs.uk/catalogue/PUB12738/nati-diab-audi-11-12-mortcomp-rep.pdf.

25. WHO. Global action plan for the prevention and control of noncommunicable diseases 2013-2020. Geneva: Organization WH; 2013.

26. Ejtahed HS, Mohtadi-Nia J, Homayouni-Rad A, Niafar M, Asghari-Jafarabadi M, Mofid V, Akbarian-Moghari A. Effect of probiotic yogurt containing Lactobacillus acidophilus and Bifidobacterium lactis on lipid profile in individuals with type 2 diabetes mellitus. J Dairy Sci. 2011:94(7):3288-94.

27. Gijsbers L, Ding EL, Malik VS, de Goede J, Geleijnse JM, Soedamah-Muthu SS. Consumption of dairy foods and diabetes incidence: a dose-response meta-analysis of observational studies. Am J Clin Nutr. 2016;103(4):1111-24.

28. Hillier TA, Pedula KL. Characteristics of an adult population with newly diagnosed type 2 diabetes: the relation of obesity and age of onset Diabetes Care. 2001;24(9):1522-7.

29. Amutha A, Mohan V. Diabetes complications in childhood and adolescent onset type 2 diabetes-a review. J Diabetes Complicat. 2016;30:951-7.

30. Saint-Eve A, Leclercq H, Berthelo S, Saulnier B, Oettgen W, Delarue J. How much sugar do consumers add to plain yogurts? Insights from a study examining French consumer behavior and self-reported habits. Appetite. 2016;99:277-84

31. Scotland N. In: Group SDSM, editor. Scottish Diabetes Survey 2013. 2013.

32. Townsend WK R, Bhatnagar P, Smolina K, Nichols M, Luengo-Fernandez R. In: Foundation BH, editor. Coronary heart disease statistics: A compendium of health statistics, 2012 edition. 2012.

33. Welsh Health Survey [http://gov.wales/statistics-and-research/welsh-healthsurvey/?tab=previous\&lang=en].

34. Shaw C, Pitcher D, Pruthi R, Fogarty D. UK Renal Registry 16th annual report: chapter 2 UK RRT prevalence in 2012: national and centre-specific analyses. Nephron Clin Pract. 2013;125(1-4):29-53.

35. Zoccali KaJ: Chronic kidney disease and end-stage renal disease - a review produced to contribute to the report 'the status of health in the European union: towards a healthier Europe. Clin Kidney J. 2009;3(3).

36. Rothwell PM, Coull AJ, Silver LE, Fairhead JF, Giles MF, Lovelock CE, Redgrave JN, Bull LM, Welch SJ, Cuthbertson FC, et al. Population-based study of event-rate, incidence, case fatality, and mortality for all acute vascular events in all arterial territories (Oxford Vascular Study). Lancet. 2005;366(9499):1773-83.

37. Zhang X, Saaddine JB, Chou CF, Cotch MF, Cheng YJ, Geiss LS, Gregg EW, Albright AL, Klein BE, Klein R. Prevalence of diabetic retinopathy in the United States, 2005-2008. J Am Med Assoc. 2010;304(6):649-56.

38. McAlpine RR, Morris AD, Emslie-Smith A, James P, Evans JM. The annual incidence of diabetic complications in a population of patients with Type 1 and Type 2 diabetes. Diabet Med. 2005;22(3):348-52.
39. Prasad S, Kamath GG, Jones K, Clearkin LG, Phillips RP. Prevalence of blindness and visual impairment in a population of people with diabetes. Eye. 2001;15(Pt 5):640-3.

40. Trautner C, Haastert B, Richter B, Berger M, Giani G. Incidence of blindness in southern Germany due to glaucoma and degenerative conditions. Investig Ophthalmol Vis Sci. 2003:44(3):1031-4.

41. Abbott CA, Carrington AL, Ashe H, Bath S, Every LC, Griffiths J, Hann AW, Hussein A, Jackson N, Johnson KE, et al. The North-West Diabetes Foot Care Study: incidence of, and risk factors for, new diabetic foot ulceration in a community-based patient cohort. Diabet Med. 2002;19(5):377-84.

42. Ahmad N, Thomas GN, Gill P, Chan C, Torella F. Lower limb amputation in England: prevalence, regional variation and relationship with revascularisation, deprivation and risk factors. A retrospective review of hospital data. J R Soc Med. 2014;107(12):483-9.

43. Johannesson A, Larsson GU, Ramstrand N, Turkiewicz A, Wirehn AB, Atroshi I. Incidence of lower-limb amputation in the diabetic and nondiabetic general population: a 10-year population-based cohort study of initial unilateral and contralateral amputations and reamputations. Diabetes Care. 2009;32(2):275-80

44. Centre NCG. Chronic heart failure: the management of chronic heart failure in adults in primary and secondary care. London: National Clinical Guideline Centre; 2010.

45. Cowie MR, Wood DA, Coats AJ, Thompson SG, Suresh V, Poole-Wilson PA, Sutton GC. Survival of patients with a new diagnosis of heart failure: a population based study. Heart. 2000;83(5):505-10.

46. Hobbs FD, Roalfe AK, Davis RC, Davies MK, Hare R. Midlands Research Practices C: Prognosis of all-cause heart failure and borderline left ventricular systolic dysfunction: 5 year mortality follow-up of the Echocardiographic Heart of England Screening Study (ECHOES). Eur Heart J. 2007;28(9):1128-34.

\section{Submit your next manuscript to BioMed Central and we will help you at every step:}

- We accept pre-submission inquiries

- Our selector tool helps you to find the most relevant journal

- We provide round the clock customer support

- Convenient online submission

- Thorough peer review

- Inclusion in PubMed and all major indexing services

- Maximum visibility for your research

Submit your manuscript at www.biomedcentral.com/submit
Biomed Central 